\title{
O que pode fazer um estagiário de psicologia na escola? problematizando prática e formação profissional ${ }^{1}$
}

What can an intern of psychology do at school? Discussing the practice and professional education

\author{
Naiana Dapieve Patias* \\ Universidade Federal do Rio Grande do Sul \\ Josiane Lieberknecht Wathier Abaid** \\ Centro Universitário Franciscano
}

Resumo A psicologia escolar dedica-se a integrar ações que facilitem a aprendizagem e o desenvolvimento da comunidade escolar. O psicólogo tem a função de rever constantemente as concepções e práticas profissionais de modo que elas possam dar conta da complexidade dessa realidade, ampliando a concepção da queixa escolar para que se identifiquem os demais fatores associados a estas queixas. Este trabalho apresenta um relato de intervenções realizadas durante um estágio em psicologia escolar, em uma escola pública do interior do RS. Percebeu-se a necessidade inicial de conscientização em relação ao papel do psicólogo, e maior aceitação de um trabalho não exclusivamente clínico. Discutem-se as práticas do psicólogo e do estagiário de Psicologia nesse contexto, no que diz respeito à educação e à saúde em sentido amplo.

PALAVRAS-CHAVE: Psicologia escolar, Relações Interpessoais, Formação acadêmica.

Abstract School psychology is dedicated to integrate actions that can facilitate the process of learning and development of scholar community. The psychologist has the function of reviewing his or her own professional concepts and practices constantly so that he or she can deal with the complexity of this reality, broadening the concept of school complaints in order to identify other factors associated with these complaints. This paper presents a report on the interventions done during an internship of school psychology at an Elementary School in the countryside of RS. It was noticed an initial necessity of awareness about the psychologist role and about a greater acceptance of a job that could not be just clinical. The practice of the psychologist and of the psychology intern in this context were discussed and related to education and health in a broad sense.

KEYWORDS: Educational psychology, Interpersonal relationships, Professional education. 


\section{Introdução}

A Psicologia Escolar ${ }^{2}$ refere-se à área da Psicologia que atua nas relações estabelecidas no contexto escolar, facilitando, assim, o desenvolvimento humano. No entanto, tal forma de atuação ainda permanece pouco conhecida, tanto pelo senso comum, quanto pelos próprios profissionais da psicologia. Segundo Valle (2003), numa perspectiva histórica, a psicologia escolar enfatizava a realização de diagnósticos classificatórios a fim de encaminhar crianças a classes especiais. Assim, sua atuação focalizava o indivíduo "problema", evitando desajustes ou desadaptações do aluno (MARTINS, 2003).

A partir da década de 80 , esse modelo passou a ser criticado na escola, além de uma preocupação com o processo de aprendizagem. A partir desse momento, houve uma re-significação da atuação do profissional de psicologia escolar de uma prática individualista para uma prática voltada ao contexto escolar e suas relações (GUZZO, 2002). Deste modo, a atuação do psicólogo voltou-se para a instituição escolar de forma a abarcar o desenvolvimento integral da comunidade escolar (ALMEIDA; GUZZO, 1992). A partir desse aspecto, o psicólogo escolar deixa o lugar de normatização para um lugar de prevenção e promoção de saúde da comunidade escolar, de forma a favorecer a qualidade e eficiência do processo educacional, através de conhecimentos psicológicos. Assim, o psicólogo escolar passa a atuar com a instituição escola e suas redes interativas.

Nessa perspectiva, conforme Martins (2003), a psicologia escolar é a área da psicologia na qual o profissional assume o papel de agente de mudanças dentro da instituição escolar. Nesse sentido, atua como o centralizador de reflexões e conscientizador de papéis representados pelos vários grupos que compõem a instituição escolar. Portanto, nesse papel, o psicólogo trabalhará as relações que se estabelecem na escola, de forma a considerar o meio social onde estas se inserem, atuando sobre a instituição escolar. Nesta perspectiva, cabe à psicologia escolar se preocupar com o clima institucional e a relação pedagógica, expressados na escola através das interações e das suas relações de poder. Com isso, a psicologia escolar deve captar todas as questões e fatos educacionais, isto é, ser uma psicologia da escola, atuar nela, estudá-la, além de considerar o cotidiano da vida dos sujeitos que dela fazem parte (LESSA; FACCI, 2011; PATTO, 1997).

Costa, Souza e Roncaglio (2003), também referem que cabe ao psicólogo escolar conhecer as forças que influenciam a escola, e a reação dessa a tais forças. Assim, esse profissional deve aplicar técnicas e conhecimentos psicológicos aos problemas apresentados na escola como um lugar total, isto é, aplicar conhecimentos a escola. Para isso, deve atuar com estratégias de intervenção para conscientizar os papéis, funções e responsabilidade de cada autor do processo escolar (GUZZO, 2002). Quanto ao termo utilizado, atualmente, alguns autores divergem quando se referem a Psicologia escolar e educacional. Uns consideram que a Psicologia Escolar e Educacional juntas fazem parte de uma área específica da psicologia, como por exemplo, Andrada (2005). Já Barbosa e Marinho-Araújo (2010) mencionam que a Psicologia Educacional refere-se à produção de conhecimentos psicológicos que se direcionam a educação, enquanto a Psicologia Escolar se direciona a aplicação dessas correntes teóricas junto à comunidade escolar. 
Quanto ao espaço físico, Andrada (2005) afirma que o psicólogo escolar necessita de um espaço onde possa escutar demandas da escola e, a partir disso, pensar em maneiras de lidar com as situações cotidianas. Cabe ressaltar que tal espaço ultrapassa uma sala de atendimentos. As atividades necessitam se dar em diferentes âmbitos escolares (OLIVEIRA; MARINHO-ARAÚJO, 2009; TADA; SÁPIA; LIMA, 2010). Dessa forma, o psicólogo escolar transita por toda a escola, de forma a não manter-se em nenhuma sala específica. De fato, ao enfatizar a prevenção, o psicólogo desse contexto pode colaborar com a propagação de informações e a transmissão de conhecimentos específicos ou diferenciados. O profissional de psicologia deve fazer isso através de linhas de ação e elementos influenciáveis em determinadas situações escolares, nesse sentido, o psicólogo deve transitar por salas de aula, pelo recreio, sala de professores, enfim, pela escola (COSTA; SOUZA; RONCAGLIO, 2003).

Quanto a problemas já diagnosticados, é necessário propiciar transformação de situações disfuncionais, o que facilita o cumprimento dos objetivos da educação. Andrada (2005), destaca que há a necessidade de o psicólogo escolar/educacional perceber a escola como um sistema, de onde provêm subsistemas que interagem entre si e que compõem o contexto escolar. Dessa forma os problemas que se apresentam na escola podem ser vistos como uma causalidade circular (pensamento sistêmico). Isso permite refletir acerca do funcionamento do sistema através de todos os subsistemas e as pessoas nele inseridas. Ou seja, quando há a queixa, o psicólogo deve investigar as multicausalidades da queixa, buscando compreendê-la para intervir.

A partir dessas considerações iniciais a respeito da psicologia escolar, enquanto um campo de atuação do psicólogo, nesse artigo serão pontuadas algumas intervenções possíveis da psicologia nessa área, a partir da experiência de estágio curricular de graduação em psicologia escolar, em uma Escola Municipal de Ensino Fundamental, de uma cidade do interior do Rio Grande do Sul, Brasil. Serão discutidas as intervenções realizadas segundo demandas que surgiram no decorrer dos meses em que a estagiária esteve na instituição de ensino conforme recomendam Lessa e Facci (2011).

\section{Método}

\section{Participantes}

Participaram do presente trabalho todos os envolvidos no contexto educacional de uma escola municipal de ensino fundamental e médio da cidade de Santa Maria no interior do Rio Grande do Sul. Essa comunidade escolar tem cerca de 25 docentes, 500 alunos e respectivos pais e/ou responsáveis, duas orientadoras educacionais, duas supervisoras educacionais, diretora, vice-diretora e quatro funcionários gerais, onde o estágio foi realizado durante oito meses.

\section{Procedimentos}

Foram utilizados como instrumentos para coleta de dados: observações do contexto escolar, conversas informais e urnas colocadas nos corredores da escola. Como ferramentas de intervenção, utilizou-se: dinâmicas em grupos operativos com adolescentes, palestras reflexivo-participantes para professores e pais, bem como intervenções pontuais em algumas turmas, conforme demandas da escola. Foi possi- 
bilitado também, aos participantes do processo educacional, orientação psicológica e, conforme necessidades, encaminhamento de crianças e adolescentes que necessitavam de apoio psicológico individual para servicos públicos das Universidades da cidade.

Primeiramente, observou-se sistematicamente a escola para detectar as demandas, o funcionamento e relações que lá se estabeleciam entre seus membros. Posteriormente, com as pessoas envolvidas no processo, foram discutidas formas de melhorar situações e problemas que "bloqueavam" o sistema como um todo. Dessa forma, investiu-se na comunicação com os pais das crianças e adolescentes, com os estudantes, professores e funcionários da escola.

\section{Resultados e discussão}

Neste trabalho, serão apresentadas e discutidas as principais intervenções realizadas pela estagiária de psicologia escolar, durante o período aproximado de oito meses. Para tanto, serão elencadas as intervenções que puderam ser efetivadas no microssistema escolar. São elas: 1) Enfrentar desafios do contexto e educar a respeito do profissional de Psicologia Escolar, 2) Acompanhamento psicológico, 3) Orientação à comunidade escolar, 4) Grupos de alunos, pais e professores, 5) Atuação em sala de aula e 6) Aumentando a interrelação entre os microssistemas escola e família.

\section{Intervenção 1: enfrentar desafios do contexto e educar a respeito do profissional de Psicologia Escolar}

A escola em questão foi muito receptiva a estagiária, apesar de anseios iniciais, por se tratar da primeira estagiária em psicologia escolar, além de nunca ter havido um psicólogo no quadro de funcionários. Apenas alguns trabalhos eventuais na área da psicologia haviam sido realizados na escola, como grupos com alunos e com professores por estagiários em nível básico e não específico. De fato, algumas dificuldades foram encontradas no que diz respeito à restrição de espaço físico, o que dificultou o trabalho da estagiária de psicologia no local, já que, muitas vezes, houve a necessidade de um espaço reservado para a escuta, o que não foi possível, principalmente no turno da tarde. Sendo assim, as intervenções ocorreram nas salas de aula, nos corredores, na sala dos professores e na sala da direção, conforme as possibilidades da escola. Essa dificuldade, no entanto, pode ser considerada formativa para estagiários, que necessitam desconstruir a idealização de que o psicólogo necessita de um espaço físico determinado para exercer sua função. Quando o psicólogo circula pela instituição, consegue visualizar melhor a dimensão psicossocial e psicoeducativa e integrar-se à equipe de trabalho, de forma a esclarecer, inclusive sua própria identidade profissional naquele grupo. Martinez (2010) argumenta que algumas formas de atuação do psicólogo neste contexto não lhes são exclusivas, como a orientação profissional ou sexual, o que tradicionalmente faz parte da prática do orientador educacional. Mas devido a sua formação pautada no funcionamento psicológico humano, pode contribuir de forma diferenciada neste contexto com seu olhar no processo subjetivo.

Em outro aspecto, percebeu-se a restrição de espaço de diálogo em diferentes grupos (professores, direção, alunos, etc) resultando em conflitos que, por vezes, desencadeavam em violência, tanto verbal quanto física. O diagnóstico de uma comunicação institucional truncada é fundamental para que se possam propor técnicas 
específicas que melhorem as relações interpessoais (DEL PRETTE; DEL PRETTE, 2008; MARTINEZ, 2010). Além disso, inicialmente, entre os professores, existia a crença de que a estagiária estava na escola para atender alunos, ou seja, uma visão do modelo clínico de psicológo dentro do contexto escolar - modelo percebido no decorrer da história do psicólogo escolar que ainda permanece no imaginário da comunidade escolar e até mesmo da população em geral (GASPAR; COSTA, 2011). Assim, surgiram muitas demandas no sentido de atendimento de alunos e, também, de alguns professores. Isso dificultou, em um primeiro momento, o trabalho da estagiária.

Essas dificuldades e modelos tradicionais de trabalho do psicólogo escolar também são encontradas em outros estudos (ANDRADA, 2005; ALMEIDA, 1999; GASPAR; COSTA, 2011, MALUF, 2003, 2005; RODRIGUES, et al. 2008). Por exemplo, no estudo de Andrada (2005) o autor menciona que uma das dificuldades do profissional diz respeito à falta de compreensão de outros profissionais da educação acerca do trabalho do psicólogo escolar. Além disso, Rodrigues et al. (2008) revela que o psicólogo que atua no contexto educativo é visto, sobretudo pelos professores, como sendo importante dentro da escola. Para os professores o psicólogo contribui para a superação das dificuldades de professores e de alunos, principalmente associado a ideia de atendimento das dificuldades e aos problemas já instalados na criança. De fato, esses aspectos tem marcado historicamente os encaminhamentos e a visão tradicional de um modelo clínico (GASPAR; COSTA, 2011; SOUZA; RIBEIRO; SILVA, 2011).

Como mencionado, essas questões foram percebidas logo no início das observações na escola onde se realizou o estágio. Quando a estagiária chegou na escola, foi-lhe dado algumas folhas com os nomes de alguns "alunos problemas" que ela devia "solucionar", "atender". A fim de suprir tais dificuldades, buscou-se informar junto a todos os envolvidos no contexto escolar sobre o trabalho que poderia ser realizado. Optou-se pela confecção de cartazes e folders informativos. Cartazes foram espalhados nos murais da escola e os folders foram distribuídos para pais, alunos, professores e funcionários da escola com o intuito de esclarecer sobre o trabalho do profissional de psicologia escolar.

Outra forma utilizada para informar a comunidade acerca do trabalho do psicólogo escolar, foi através de conversas informais com a direção, professores e pais. No entanto, ainda percebeu-se a dificuldade de comunicação, sendo que a equipe diretiva e os professores solicitavam atendimento clínico aos alunos. Por isso, retomava-se semanalmente, o objetivo do trabalho a ser realizado.

\section{Intervenção 2: acompanhamento psicológico}

De acordo com Guzzo (1996), é preciso que o psicólogo escolar desloque o seu foco de atuação da doença para a saúde, do fracasso para o do sucesso, dos distúrbios e dificuldades, para o das competências e qualidades. De fato, as principais intervenções foram realizadas no sentido de grupo, da comunidade escolar e não com foco no indivíduo ("aluno problema"). Assim, houve uma prática mais contextualizada, participativa e criativa junto aos professores e aos alunos, com a função de mediação das relações interpessoais.

No entanto, como citado anteriormente, muitos professores e até mesmo pais, possuiam a demanda de atendimento de alunos, a partir de queixas sobre proble- 
mas de aprendizagem e comportamento. De acordo com Del Prette (2002) uma das alternativas de atuação do profissional de psicologia escolar refere-se ao diagnóstico e ao encaminhamento de problemas relacionados à queixa escolar. É papel do psicólogo da escola poder acompanhar casos nos quais há maiores dificuldades em relação a escolarização. Por outro lado, ressalta-se que o papel do psicólogo escolar é muito mais amplo. Primeiramente, é importante que se possam investigar causas contextuais, no ambiente escolar, da sala de aula, relação professor-aluno para após, focar a investigação individualmente (RODRIGUES et al., 2008).

A estagiária pode fazer isso através de conversas informais psicoeducativas com pais, professores, diretor, supervisor e orientador escolar. Subsequentemente, houve necessidade de acompanhamento de alguns alunos que se encontravam com dificuldades educacionais dentro do âmbito escolar. Foi dado, então, a esses alunos, um acompanhamento psicológico e o apoio a seus pais também. Esses acompanhamentos foram realizados com o objetivo de minimizar efeitos relativos às dificuldades que esses alunos vinham apresentando no contexto escolar.

A escuta foi realizada conforme demanda de cada criança/adolescente. No geral, essa escuta ocorreu semanalmente com cada aluno individualmente, utilizandose de espaço lúdico e conversas com o aluno e seus pais e/ou responsáveis, separadamente. Alguns alunos que necessitavam de atendimento clínico individual foram encaminhados ao Laboratório de práticas profissionais do curso de Psicologia de uma instituição de ensino superior da mesma cidade. Cabe destacar, como enfatiza Martinez (2010), que a prática de encaminhamento "sem uma situação exepcional que a justifique" (p. 44), tem sido nociva por contribuir com a crença de pais e professores de que a criança tem sérios problemas e, até mesmo, ocasionar outras dificuldades que não existiam. Dessa forma, essa ação deve ser evitada sempre que possível.

\section{Intervenção 3: orientação à comunidade escolar}

De acordo com Rodrigues et al. (2008), o psicólogo escolar deve trabalhar com prevenção e promoção de saúde, sendo seu foco principal a saúde e não a doença. Nesse sentido, a prevenção primária engloba ações voltadas a grupos amplos que ainda não apresentam dificuldades e antecede o surgimento de problemas psicológicos. Visa ao desenvolvimento de competências específicas que propiciem o bem-estar e a qualidade de vida dos sujeitos. Já, a prevenção secundária volta-se para populações ou para subgrupos que já exibem sinais precoces de problemas psicológicos. Assim, as ações envolvem um nível de atenção focalizado em grupos de risco ou em intervenções preventivas que inibam problemas emergentes nesse grupo. Por fim, a prevenção terciária busca minimizar os efeitos e reduzir as consequencias de uma doença já instalada (RODRIGUES et al, 2008).

Assim, no referido estágio em psicologia escolar, algumas intervenções foram realizadas no sentido de prevenir doenças e promover saúde na escola. Ủma das ações importantes realizadas, foi a orientação psicológica para pais e professores a fim de evitar que problemas pudessem surgir (prevenção primária) e também minimizar dificuldades e problemas já existentes (prevenção secundária e terciária), tais como: problemas de comportamento e aprendizagem, dificuldades no relacionamento entre professores e alunos, entre professores e entre a família e a escola. Conforme as necessidades constatadas e demandas que surgiram dos próprios pais, que vinham em 
busca de ajuda ou de professores, foram realizadas orientações psicológicas tanto para pais, como para professores, algumas vezes através de conversas informais e outras mais formais.

A esse respeito, Costa et al. (2003), mencionam que uma das formas de se pensar a orientação no contexto escolar, é estabelecer uma boa relação entre duas pessoas, na qual uma delas é ajudada a resolver dificuldades de ordem educacional, profissional, vital e podendo se utilizar melhor dos seus recursos pessoais. Assim, pode acontecer a orientação individualmente e/ou em grupo.

Nesse aspecto, foram criados espaços de escuta para as demandas que surgiam na escola, oriundas, principalmente, da educação pais/filhos. Essas intervenções, através da orientação psicológica, foram realizadas informalmente dentro do espaço escolar, além de formalmente, e por meio de agendamentos. As orientações se deram pela criação de espaços de escuta que foram realizados individualmente com cada pai, professor ou equipe diretiva. Também houveram palestras com professores e pais onde foram discutidas teorias, exemplos e situações cotidianas das relações professor-aluno e pais-filhos com o objetivo de estimulá-los a discutirem e buscarem estratégias conjuntas e específicas ao seu papel, de forma a encontrar novas opções e condições de ajuda mútua (POLÔNIA; DESSESN, 2005). Assim, foram pensadas novas formas de educar e de se relacionar tanto no contexto escolar como no contexto familiar, possibilitando um maior repertório comportamental através de práticas educativas como fator de proteção para o desenvolvimento na infância e adolescência (ANDRADA, 2005; RIOS; WILLIAMS, 2008; WEBER; VIEZZER; BRANDENBURG, 2004).

\section{Intervenção 4: grupos de alunos, pais e professores}

O profissional de Psicologia escolar, pode, como forma de intervenção, realizar grupos de alunos, pais e professores na escola (OUTEIRAL; CEREZER, 2005). No referido estágio, optou-se pelos grupos operativos, os quais foram realizados com alunos, pois não houve, na época, aceitação da realização de grupos com os professores. Também, não existiu a possibilidade de realização de grupo com os pais dos alunos, devido a falta de horário de estágio na escola.

No que diz respeito aos grupos operativos, conforme Osório (2000), estes são definidos como grupos centrados na tarefa, a qual é considerada essencial. Deste modo, o que caracteriza os grupos operativos é a relação que seus integrantes mantêm com a tarefa. Esta tarefa pode ser tanto a obtenção da cura (grupo terapêutico), quanto à aquisição de conhecimentos (grupo de aprendizagem). Para o mesmo autor, a importância de um grupo operativo se dá em função de resolução de situações estereotipadas e obtenção de mudanças. Assim, "o grupo operativo é um instrumento de trabalho, um método de investigação e cumpre, além disso, uma função terapêutica” (OSÓRIO, 1989).

No estágio em Psicologia escolar, foram realizados dois grupos operativos, sendo um em cada semestre de estágio. O primeiro foi efetivado no período de outubro a dezembro. A demanda surgiu a partir da reclamação de professores no que dizia respeito a uma turma específica da escola. Foi proposto, assim, um grupo onde poderiam ser tratados assuntos do interesse dos adolescentes. Conforme o interesse 
de cada aluno, realizou-se uma lista dos interessados em participar. Oito meninas se inscreveram, sendo que apenas cinco permaneceram até o último encontro.

Os encontros ocorreram semanalmente, em horários cedidos pela escola com duração de uma hora e trinta minutos. No final do processo, percebeu-se um crescimento e uma forte vinculação entre todas as integrantes do grupo sendo que, no início, nem todas se conheciam e possuíam representações diferentes do que cada pessoa podia ser. No último encontro do grupo, todas expressaram a importância da rede de apoio que o grupo forneceu para dificuldades familiares, angústias e dúvidas as quais foram sempre acolhidas pelo grupo.

O segundo grupo teve início em abril, ocorreu semanalmente, com duração de uma hora e trinta minutos, em dia e espaço cedido pela escola. Foi realizado em função da demanda observada na escola, através de situações que diziam respeito à emergência da sexualidade dos alunos, além do pedido destes como forma de sugestão ao trabalho da psicologia escolar. O grupo foi composto de oito pessoas, sendo dois meninos e seis meninas. Durante os encontros, os participantes do grupo apresentaram muitas duvidas, curiosidades e tabus relativos a sexualidade que, ao final, puderam ser catalizados no, e pelo, grupo.

Segundo Carvalho, Rodrigues e Medrado (2005), grupos sobre sexualidade com adolescentes possibilitam a modificação de atitudes e comportamentos, propiciando o estabelecimento de relações entre a vivência da sexualidade com sua saúde e saúde do corpo. Tendo um maior conhecimento do corpo e os riscos de determinados comportamentos, o adolescente pode elaborar seu projeto de vida visando lidar com a sexualidade de forma mais responsável, tranqüila e saudável. No grupo sobre sexualidade, realizado na escola, percebeu-se que os espaços de expressão e elaboração sobre a sexualidade são insuficientes, pois, na percepção dos adolescentes, não há um espaço na escola para que possam falar a respeito de suas dúvidas, e, quando há, não se sentem seguros para vencerem a timidez.

\section{Intervenção 5: atuando em sala de aula}

Identificou-se também, no decorrer do estágio, uma necessidade de manifestação comportamental violenta dos alunos nas séries iniciais, conforme a fala dos professores da escola e de ações de alunos em sala de aula e recreio. Para ajudar as crianças a entender seus sentimentos, diminuir a culpa que sentiam devido a comportamentos impulsivos e à dificuldade de expressar os sentimentos, foi proposto a duas professoras, uma intervenção estruturada para trabalhar formas de percepção de sentimentos junto a turmas de alunos do segundo e quarto ano.

Em um período cedido pelo professor, foram aplicadas técnicas gráficas e expressivas para que os alunos tivessem a oportunidade de identificar os diferentes sentimentos que existem. Os encontros subseqüentes abordaram dramatizações de situações com os colegas e professores visando desenvolver a capacidade de empatia das crianças. Nos encontros finais, foram utilizadas técnicas gráficas e artísticas para que os participantes desenvolvessem novas estratégias de expressão de sentimentos. A medida em que reconheciam suas próprias inquietações, poderiam encontrar outras formas de manifestação de frustrações, raiva e tristeza, que não fossem agressivas (MILLER, 2008). 
As atividades realizadas foram muito bem recebidas pelas crianças. Da mesma forma, as professoras compreenderam a importância da atividade e auxiliaram, incentivando a participação dos alunos. De forma geral, os participantes demonstraram habilidades insuficientes para nomear, reconhecer e entender plenamente certos sentimentos e acontecimentos que estão ocorrendo em sua vida. Entretanto, foram receptivos e reconhecem a importância de aprendizagens como essas.

Foi possível detectar pequenas modificações observáveis no comportamento das crianças, tais como, uma maior afetividade em relação aos colegas e uma menor agressividade. No entanto, essas modificações persistiram por pouco tempo, indicando a necessidade de se desenvolver o trabalho de forma contínua. No relato dos professores e de alguns pais, evidenciou-se a percepção da importância do trabalho realizado e muita empolgação por parte das crianças. Assim, pais e professores pediram que mais atividades como essas pudessem ser realizadas.

\section{Intervenção 6: aumentando a interrelação entre os microssistemas esco- la e família}

Observou-se a pequena participação da família na escola e uma falta de colaboração entre os microssistemas, o que acarretou em dificuldades, pois a escola culpava a família pelos problemas comportamentais e de aprendizagem dos alunos e a família culpava a escola. Havia um jogo do tipo "ping-pong" onde não se buscavam as resoluções dos problemas, mas sim os culpados pela não-aprendizagem ou pelo "mau comportamento" da criança.

A família participava da escola apenas quando chamada para ouvir reclamações ou para buscar os boletins. Outros encontros da família com a escola se davam através das formalidades do dia das mães e dos pais. Não havia um objetivo em comum entre os microssistemas, e existia uma falta de confiança, que afetava a maneira como os alunos percebiam o microssistema escola - "escola não é importante"; "não gosto da professora”; “a escola é uma bagunça”; "aqui eu posso tudo" - concepções percebidas muitas vezes pelos pais e que afetavam a maneira como as crianças agiam no ambiente escolar.

A esse respeito, deve-se considerar que a relação do aluno com a escola é afetada pela significação que os pais dos alunos dão a ela, aos estudos dos filhos e as relações dele com os demais alunos (OUTEIRAL, 2005). Além disso, segundo Polônia e Dessen (2005), há benefícios quando existe uma boa integração entre família e escola, bem como há implicações de uma falta de integração entre esses microssitemas, pois quando estes mantêm boas relações, são maximizadas as condições para um melhor aprendizado e desenvolvimento da criança (PATIAS; ABAID; GABRIEL, 2011).

Além disso, Silveira e Wagner (2009), mencionam que a existência de canais de comunicação e de participação entre a vida familiar e escolar pode favorecer o desenvolvimento infantil e a relação família-escola. Partindo-se do pressuposto de que, tanto pais quanto professores ocupam lugares distintos e cumprem funções diferentes, considera-se que as interações entre eles e a complementaridade de suas funções na educação de crianças e adolescentes é algo positivo. 
No entanto, na escola não havia um espaço de interação entre os familiares e as crianças no contexto escolar em que não houvesse queixa sobre o comportamento das criancas, de forma que os pais apenas eram chamados na escola, para os professores queixarem-se de seus filhos. Da mesma forma, não havia a valorização da escola para a família e da família para a escola. Assim, propôs-se uma atividade com o objetivo de aproximar os pais do ambiente escolar, sendo esse aspecto de extrema importância (HABIGZANG et al. 2004). Com esse intuito, foi realizada, além da palestra para pais, como forma de orientação e aproximação à escola, "O dia da família na escola com a Galeria de arte da turma”, em uma turma do ensino fundamental. A escolha dessa turma para intervencao deu-se pelo fato de haver reclamações dos professores pela falta de comprometimento do pais com os filhos. Dessa forma, primeiramente, foram realizadas intervenções com as crianças, em sala de aula, onde foi proposto que desenhassem a família real e a ideal. Após, os alunos deveriam desenhar pessoas importantes para elas. Outros desenhos foram realizados com a professora em sala de aula e cada um, individualmente, deveriam escolher os desenhos que iriam compor o mural para posterior galeria de arte. Para a galeria, foram convidados pais, familiares, amigos, parentes e vizinhos, para que pudessem apreciar o material confeccionado pelas crianças. Chegado o dia da galeria de arte, apenas um pai de um aluno compareceu. No entanto, no dia anterior, a mãe de uma aluna foi olhar os desenhos.

Percebeu-se assim, a dificuldade da aproximação entre escola e família, pois essa se dava apenas por reclamações e desavenças. Quando houve oportunidade de um espaço diferenciado no qual família e escola pudessem compartilhar alegrias, a família não compareceu. Ficou a sensação de que a família não apresentou-se a escola pois estava "acostumada" a ser chamada apenas quando algo "ruim" acontecia. Nesse sentido, é importante que, aos poucos, trabalhos como esses sejam implantados na escola, para que se comece a produzir um novo sentido, uma nova colaboração entre família e escola para que possam, juntas, auxiliar na aprendizagem das crianças.

\section{Considerações finais}

Nesse trabalho pretendeu-se socializar, através da experiência em psicologia educacional, as possíveis intervenções que esse profissional pode executar enquanto agente de mudanças no interior da escola, sobretudo quando se trata de um trabalho de inserção e construção do lugar de psicólogo. Não foi intenção deste artigo engessar as práticas, mas revelar como pequenas intervenções podem produzir mudanças no contexto escolar ampliado. Dessa forma, é possível que o profissional de psicologia escolar possa ter foco na escola como um todo, apesar das dificuldades ainda presentes no cotidiado de atuação desse profissional. Os empecilhos encontrados reforçam que as dificuldades de algumas famílias em estabelecer laços com a escola necessitam ser trabalhadas para que não impeçam uma maior efetivação das propostas do psicólogo escolar e respectivos estagiários.

Assim, o profissional deve estar atento as manifestações da escola no que diz respeito a aspectos que "atrapalham" o caminho da educação, seja nas relações interpessoais, seja por dificuldades pedagógicas ou organizacionais. O psicológo deve, estar atento às demandas manifestas e latentes, para que sua atuação seja mais eficaz e realmente possa dar conta do ambiente escolar. 
Quando todos estão unidos por uma causa, os problemas podem ser minimizados e isso é possível. Como dizia Paulo Freire (1996): "[...] É o meu bom-senso, em primeiro lugar, o que me deixa suspeitoso, no mínimo, de que não é possível à escola, se, na verdade, engajada na formação dos educandos e educadores, alhear-se das condições sociais culturais, econômicas de seus alunos, de suas famílias [...] (p. 63).

\section{Referências}

ALMEIDA, S. F. de. O psicólogo no cotidiano da escola: re-significando a atuação profissional. In: GUZZO, R. S. (Org). Psicologia escolar: LDB e a educação hoje. Campinas, SP: Alínea, 1999, p.77-90.

ALMEIDA, L.; GUZZO, R.S. . A relação psicologia e educação: perspectiva histórica do seu âmbito e evolução. Estudos de Psicologia, v. 9, n3, p. 117-131, 1992. Disponível em: <www. scielo.br>. Acesso em: 02 de março de 2009.

ANDRADA, E. G. Novos Paradigmas na prática do psicólogo escolar. Psicologia Reflexão e Crítica, v.18,n.2, p. 196-199, 2005. Disponível em: <www.scielo.br/pdf/prc/v18n2/27470.pdf〉. Acesso em: 03 de março de 2009.

BARBOSA, R. M.; MARINHO-ARAÚJO C. M. Psicologia escolar no Brasil: considerações e reflexões históricas. Estudos de Psicologia (Campinas), v. 27 n3, p. 393-402, 2010. Disponível em: <www.scielo.br/pdf/estpsi/v27n3/11.pdf >. Acesso em: 04 de outubro de 2011.

CARVALHO, A. M., RODRIGUES, C. S.; MEDRADO, K. S. (2005). Oficina em sexualidade humana com adolescentes. Estudos de Psicologia, v. 10, n. 3, p. 377-384, 2005. Disponível em: <http://www.scielo.br/scielo.php?script=sci_arttext\&pid=S1413-294X2005000300006>. Acesso em: 03 de maio de 2009.

COSTA, C. R.; SOUZA, I. E. ; RONCAGLIO, S. M. Momentos em Psicologia Escolar. 2a ed. $3^{a}$ triagem. Curitiba: Juruá, 2003.

DEL PRETTE, Z. A. P. Psicologia, educação e LDB: novos desafios para velhas questões? In: Guzzo, R. (org). Psicologia Escolar: LDB e educação hoje. São Paulo: Alínea, 2002, p.11-34.

DEL PRETTE, A.; DEL PRETTE, Z. A. P. Psicologia das relações interpessoais: vivências para o trabalho em grupo. $7^{\mathrm{a}}$ Ed. Petrópolis, Rio de Janeiro: Vozes, 2008.

FREIRE, P. Pedagogia da autonomia: Saberes necessários à prática educativa. São Paulo: Paz e Terra, 1996.

GASPAR, F. D.; COSTA, T. A. . Afetividade e atuação do psicólogo escolar. Revista Semestral da Associação Brasileira de Psicologia Escolar e Educacional, v. 15, n.1, p. 121-129, 2011. Disponível em: <http://www.scielo.br/scielo.php?pid=S1413-85572011000100013\&script=sci_arttext>. Acesso em: 22 de janeiro de 2012.

GUZZO, R. S. L . Formando Psicólogos Escolares No Brasil: Dificuldades e Perspectivas. In: S. M. WECHSLER. (Org.). Psicologia escolar: pesquisa,formação e prática. 1 ed, v.1. Campinas - São Paulo: Alínea, 1996, p.75-92.

GUZZO R. S. L. (Org). Psicologia Escolar: LDB e educação hoje. São Paulo: Alínea, 2002.

HABIGZANG, L. et al. A violência no contexto escolar e a inserção ecológica da Psicologia: um relato de experiência. In. S. H. KOLLER, Ecologia do desenvolvimento humano. São Paulo: Casa do Psicólogo, 2004, p. 355-380.

LESSA, P. V.; FACCI, M. G. A atuação do psicólogo no ensino público do Estado do Paraná. Revista Semestral da Associação Brasileira de Psicologia Escolar e Educacional, v. 15, n. 1, p. 131-141, 2011. Disponível em: <http://www.scielo.br/scielo.php?pi$\mathrm{d}=$ S1413-85572011000100014\&script=sci_arttext $>$. Acesso em: 02 de dezembro de 2011. 
MALUF, M. R. Psicologia escolar: novos olhares e o desafio das práticas. In ALMEIDA, S. F. (Org). Psicologia escolar: compromisso, ética e competências na formação e atuação profissional., Campinas, São Paulo: Alínea, 2003, p.135-146.

MALUF, M. R. O psicólogo escolar e a alfabetização. In. A. M. MARTINEZ (org). Psicologia escolar e compromisso social, Campinas, São Paulo: Alínea, 2005, p.67-92.

MARTINS, J. (2003). A atuação do Psicólogo Escolar: Multirreferencialidade, implicação e escuta clínica. Psicologia em Estudo. Maringá, v. 8, n.2, p. 39-45, 2003. Disponível em: <http:// www.scielo.br/scielo.php?pid=S1413-73722003000200005\&script=sci_arttext $>$. Acesso em: 07 de julho de 2009.

MARTINEZ, A. M. (2010). O que pode fazer o psicólogo na escola? Em Aberto, v. 23, n. 83, p. 39-56. Disponível em: <www.rbep.inep.gov.br/index.php/emaberto/article/view/1634/1298>. Acesso em: 20 de janeiro de 2012.

MILLER, K. Educação Infantil: Como lidar com situações difíceis. Porto Alegre: ArtMed, 2008.

OLIVEIRA, C. B.; MARINHO-ARAÚJO, C. M. . Psicologia escolar: Cenários atuais. Estudos e Pesquisas em Psicologia. v. 9, n. 3, p. 648-663, 2009. Disponível em: <www.revispsi.uerj. br/v9n3/sumariov9n3.html>. Acesso em: 08 de agosto de 2011.

SOUZA, C. S.; DE, RIBEIRO, M. J.; SILVA, S. DA M. . A atuação do psicólogo escolar na rede particular de ensino. Revista Semestral da Associação Brasileira de Psicologia Escolar e Educacional, v. 15, n. 1, p. 53-61, 2011. Disponível em: <http:/www.scielo.br/scielo.php?pi$\mathrm{d}=\mathrm{S} 1413-85572011000100006 \&$ script=sci_arttext $>$. Acesso em: 19 de janeiro de 2012.

OSÓRIO, L. C. Grupoterapia Hoje. Porto Alegre: Artes Médicas, 1989.

OSÓRIO, L. C. Grupos: teorias e práticas acessando a era da grupalidade. Porto Alegre: Artes Médicas, 2000.

OUTEIRAL, J. O. Trabalho com Grupos na Escola. In. J. O. OUTEIRAL; C. CEREZER. O mal - estar na escola. 2a ed. Rio de Janeiro: Revinter, 2005, p.9-22.

PATIAS, N. D.; ABAID, J. L. W.; GABRIEL, M. R. Concepções de família na escola. Psicopedagogia On Line, s/v, 2011. Disponível em: <http://www.psicopedagogia.com.br/new1_artigo.asp? entrID=1390>. Acesso em: 09 de dezembro de 2011.

PATTO, M. H. S. (org). Introdução à psicologia escolar. 3 ed. São Paulo: Casa do Psicólogo, 1997.

POLONIA, A. C.; DESSEN M. A. Em busca de uma compreensão das relações entre família e escola. Psicologia Escolar e Educacional, Campinas, v.9 n2, p. 303-312, 2005. Disponível em: <http://www.scielo.br/scielo.php?pid=S1413-85572005000200012\&script=sci_arttext >. Acesso em: 04 de maio de 2009.

RIOS, K. A.; WILLIAMS, L. C. Intervenção com famílias como estratégia de prevenção de problemas de comportamento em crianças: uma revisão. Psicologia em estudo, v. 13, n4, p. 799-806, 2008. Disponível em: <http://www.scielo.br/scielo.php?pi$\mathrm{d}=$ S1413-73722008000400018\&script=sci_arttext>. Acesso em: 27 de julho de 2009.

RODRIGUES, M. C. et al. Prevenção e promoção de saúde na escola: concepções e práticas de psicólogos escolares. Gerais: Revista Interinstitucional de Psicologia, v. 1, n. 1, p. 67-78, 2008. Disponível em: <www.fafich.ufmg.br/gerais/index.php/gerais/article/.../9/3>. Acesso em: 18 dezembro de 2011.

SILVEIRA, L. M., ;WAGNER, A. Relação família-escola: práticas educativas utilizadas por pais e professores. Revista semestral da Associação brasileira de Psicologia escolar e Educacional, v. 13, n. 2, p. 283-291, 2009. Disponível em: <www.scielo.br/pdf/pee/v13n2/v13n2a11. pdf $>$. Acesso em: 19 de setembro de 2010. 
TADA, I. N.; SÁPIA, I. P.; LIMA, V. A. Psicologia Escolar em Rondônia: formação e práticas. Revista Semestral da Associação Brasileira de Psicologia escolar e educacional, v. 14, n. 2, p. 333-340, 2010. Disponível em: <http://www.scielo.br/scielo.php?script=sci_arttext\&pi$\mathrm{d}=$ S1413-85572010000200015> . Acesso em: 29 de agosto de 2011.

VALLE, L. E. Psicologia Escolar: um duplo desafio. Psicologia ciência e profissão, v. 23, n.1, p. 22-29, 2003. Disponível em: <http://pepsic.bvsalud.org/scielo.php?pi$\mathrm{d}=$ S1414-98932003000100004\&script=sci_abstract $>$. Acesso em: 08 de maio de 2010.

WEBER, L. N.; VIEZZER, A. P.; BRANDENBURG, O.J. O uso de palmadas e surras como prática educativa. Estudos de Psicologia, Natal v. 9, n. 2, p. 227-237, 2004. Disponível em: <http://redalyc.uaemex.mx/pdf/261/26190204.pdf>. Acesso em: 10 abril de 2009.

\section{Notas}

${ }^{1}$ Este artigo foi escrito a partir da experiência de Estágio Específico I e II, ênfase em Psicologia Educacional, durante a graduação da primeira autora em Psicologia em um Centro Universitário, supervisionada pela segunda.

${ }^{2}$ Neste artigo as autoras optaram por utilizar tanto o termo "escolar" quanto "educacional" por entenderem que as duas denominações estão mutuamente implicadas ao papel do psicólogo.

* Doutoranda em Psicologia pela Universidade Federal do Rio Grande do Sul,. Porto Alegre, Rio Grande do Sul - Brasil.

** Professora Doutora em Psicologia pela Universidade Federal do Rio Grande do Sul,. Porto Alegre, Rio Grande do Sul - Brasil.

\section{Correspondência}

Naiana Dapieve Patias - Universidade Federal do Rio Grande do Sul, Instituto de Psicologia. Rua Ramiro Barcelos, 2600,1º andar, Santa Cecília - Porto Alegre, Rio Grande do Sul - Brasil.

E-mail: naipatias@hotmail.com - josianelieb@unifra.br

Recebido 23 de julho de 2012

Aprovado em 20 de novembro de 2013 
